\title{
E09
}

\section{Inferring Sealing Properties of Faults in Carbonates by Comparing Field Examples with Stress Evolutionary Models}

\author{
I. Mannino* (Roma Tre University), P. Cianfarra (Roma Tre University) \& F. \\ Salvini (Roma Tre University)
}

\section{SUMMARY}

Permeability in carbonates is strongly influenced by the presence of fracture patterns. Carbonate rocks achieve fracturing both during diagenesis and tectonic processes. Spatial distribution of brittle deformation rules the secondary permeability of carbonatic rocks and therefore the accumulation and the pathway of deep fluids (ground-water, hydrocarbon). This is particularly true in the development of faults where damage zone and fault core show different hydraulic properties. In this work we studied the brittle deformation in carbonates related to fault kinematics to better understand the hydraulic properties of fault rocks. Quantitative analyses of brittle deformation from field measurements were compared to numerical models performed by FRAPtre software. This numerical tool allows to study the 4D evolution of stress/ brittle deformation in fault related rocks. 


\section{Fault and Top Seals}

\section{Introduction}

Permeability in carbonates is strongly influenced by the presence of fracture patterns. Carbonate rocks achieve fracturing both during diagenesis and tectonic processes. Spatial distribution of brittle deformation rules the secondary permeability of carbonatic rocks and therefore the accumulation and the pathway of deep fluids (ground-water, hydrocarbon). This is particularly true in the development of faults where damage zone and fault core (Chester et al., 1993; Caine et al, 1996) show different hydraulic properties (Antonellini et al., 2008; Billi et al, 2003; Evans et al., 1997; Knipe, 1997; Manzocchi et al., 1999; Storti et al., 2003). In this work we studied the brittle deformation in carbonates related to fault kinematics to better understand the hydraulic properties of fault rocks. Quantitative analyses of brittle deformation from field measurements were compared to numerical models.

\section{Methods and discussions}

Field examples from previous studies showed that the development of faults in carbonate rocks can be described as a two-step process (Storti, 2007). In the initial step, deformation in the fault zone is dominated by fracturing processes that include joints, smaller scale faulting (e.g. R and R' planes), and pressure solution surfaces. This initial brittle deformation stage produces a damage zone with an increase in the permeability. As the stress effectiveness in producing brittle deformations (the Deformation Function, $\mathrm{D}_{\mathrm{f}}$ ) increases, either or both by time or change in values, the fracture intensity increases until the rock is broken into clasts with the proper shape that allows relative movements among them. This marks the beginning of the second step, where these relative movements on the one hand ease the fault slip, that concentrates in the fault core, and on the other hand induce further fragmentation by the grinding of the clasts, with the development in the fault core of a characteristic grain size distribution of increasing fractal dimension (Sammis et al., 1986; Billi et al., 2003, 2007). This results in a dramatic reduction in permeability across the fault that becomes a seal. This contrasts with higher permeability values preserved along the sides of the faults, due to the presence of the fractured damage zones. Since fracturing results from stress conditions in fault zones, the fracturing evolution of a fault zone can be numerically simulated at each discrete portion of a fault plane by integrating the failure capability (i.e. the $\mathrm{D}_{\mathrm{f}}$, eq. 1) through time during the fault evolution through time (the Time Stress Integral, TSI, see eq. 2).

$D_{\mathrm{f}}=\tau^{*}-\Sigma$

where: $\mathbf{D}_{\mathbf{f}}$ is the deformation function; $\boldsymbol{\tau} *$ is the effective stress; $\boldsymbol{\Sigma}$ is the rock strength

TSI $=\int \mathbf{F}\left(\phi, \sigma, \Sigma_{\mathrm{e}}\right) \mathrm{dt}$

where: $\phi$ is the frictional coefficient; $\boldsymbol{\sigma}$ is the stress ; $\Sigma_{\mathrm{e}}$ is the strength

The TSI value represents the time-cumulative deformation function that acted on the given part of the structure and is measured in Pa by Time (year). Quantitative spatial analyses of brittle deformations in fault core and damage zones of faults in carbonates were performed in Meso-Cenozoic carbonate units of the Latium-Abruzzi Platform, Southern Apennines, Italy. These analyses were done at Jenne site (Roma, Italy) where Dogger-Lower Cretaceous peloidal mudstone and wackstone and Upper Cretaceous-Paleocene grainstone and packstone outcrop. The brittle deformation of middle Miocene fine packstone and grainstone (Briozoi and Litotamni Formation) was analysed in Pietrasecca site (L'Aquila, Italy). For each of these faults their stress/brittle deformation evolution was modeled as the TSI integration by a numerical approach (FRAPtre software, see Fig. 1). FRAPtre is a true 4D tool that can predict stress conditions, brittle deformation patterns, and permeability architecture associated to given set of fault surfaces during single or multiple tectonic events and under possibly different stress conditions. Results provided by FRAPtre include: rheological properties of the faulted rocks; deformation structure type (joints, pressure-solution cleavages), their attitude, and their probability; prediction of the occurrence and location of fault gouge layers. 


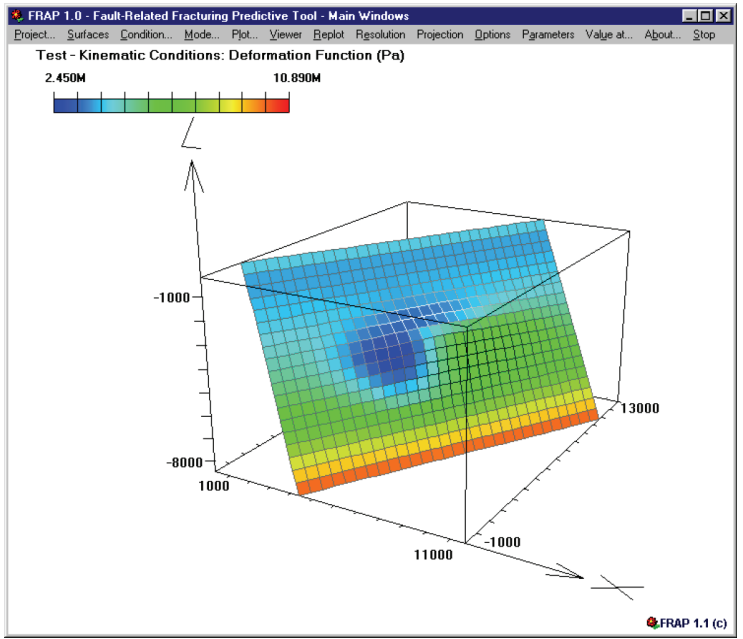

Figure 1 - FRAPtre fault plane numerical modeling.

\section{Conclusions}

Preliminary results from the comparison confirmed the two-step evolution of faults and showed that the fault-core development (i.e. the sealing of the fault) starts in a relatively later stage, after the fault displacement overrides the critical value. The development of the damage zone characterizes the initial stage of fault evolution and produces an increase in the permeability. Distribution of TSI values computed by the numerical modeling provides a useful tool for a quantitative prediction of fault related fracturing distribution.

\section{References}

Antonellini, M., Tondi, E., Agosta, F., Aydin, A. and Cello, G. [2008] Failure modes in deepwater carbonates and their impact for fault development: Majella Mountain, Central Apennines, Italy. Marine and Petroleum Geology, 25, 1074-1096.

Billi, A., Salvini, F. and Storti, F. [2003] The damage zone -fault core transition in carbonate rocks: implications for fault growth, structure and permeability. Journal of Structural Geology 25, 1779-1794.

Billi, A., [2007] On extent of size range and power low scaling for particles of natural carbonate fault cores. Journal of Structural Geology 29, 1512-1521.

Caine, J., S., Evans, J., P. and Forster C. B. [1996] Fault architecture and permeability structure. Geology 24, 1025-1028.

Chester, F., M., Evans, J., P., Biegel, R.,L. [1993] Internal structure and weakening mechanism of San Andreas Fault. Journal of Geophysical research 98, 771-787.

Evans, J., P., Forster C., B. and Goddard J., V. [1997] Permeabilities of fault-related rocks and implications for fault-zone hydraulic structure. Journal of Structural Geology 19, 13931404.

Knipe, R., J. [1997] Juxtaposition and seal diagrams to help analyze fault seals in hydrocarbon reservoirs. American Association of Petroleum Geologists Bulletin, 81, 187-195.

Manzocchi, T., Walsh, J., J., Nell, P. and Yelding G. [1999] Fault transmissibility multipliers for flow simulation models. Petroleum Geoscience 5, 53-63.

Sammis, C., Osborn, R., H., Anderson, J.,L., Banerdt, M. and White, P. [1986] Self-similar cataclasis in the formation of fault gouge. Pure Appl. Geophys., 124, 54-77.

Storti, F., Billi, A. and Salvini, F. [2003] Particle size distributions in natural carbonate fault rocks: insights for-self-similar cataclasis. Earth Planet. Sci. Lett., 206, 173-186.

Storti, F., Balsamo, F., Salvini, F. [2007] Particle shape evolution in natural carbonate granular wear materiel, Terra Nova, 19 1-9. 